\title{
Mudanças na vida das pessoas com lesão medular adquirida
}

\author{
Changes in the life of people with acquired spinal cord injury
}

Cambios en la vida de personas con lesión medular adquirida

\begin{abstract}
Soraia Dornelles Schoeller ${ }^{1}$, Rodolfo Nunes Bitencourt ${ }^{2}$, Maria Tereza Leopardi ${ }^{3}$, Denise Pires de Pires ${ }^{4}$, Maria Tereza Brasil Zanini ${ }^{5}$
\end{abstract}
\section{RESUMO}

A lesão medular é uma deficiência física de grande impacto pessoal e social. É grave e incapacitante. O objetivo geral deste estudo foi compreender quais são os impactos da lesão medular na vida da pessoa por ela acometida. Investigaram-se também algumas características das pessoas, realização das atividades da vida diária, a vida antes da lesão e os recursos procurados no momento da lesão. Trata-se de estudo de abordagem qualitativa, exploratória e descritiva. Os participantes foram pessoas com lesão medular há mais de dois anos. A coleta de dados baseou-se em entrevista semiestruturada. Os resultados da pesquisa mostraram que a pessoa divide sua vida entre antes, durante e depois da lesão, revivendo o momento gerador diversas vezes. A família é essencial na (re)adaptação da pessoa. É necessário que o enfermeiro aprimore os conhecimentos sobre lesão medular e seus cuidados, para fornecer suporte à pessoa, sua família e equipe de saúde.

Descritores: Cuidados de Enfermagem; Reabilitação; Traumatismos da medula espinhal.

\section{ABSTRACT}

Spinal cord injury is a serious and incapacitating physical impairment with a strong personal and social impact. The general objective of this study was to understand what impacts the spinal cord injury has on the lives of those affected. The study also investigated some characteristics of the individuals, the performance of activities of daily living, life before the injury and the resources sought at the moment of the injury. This is a qualitative, exploratory and descriptive study. The participants were individuals living with spinal cord injury for over two years. Data were collected using semi-structured interviews. The study results showed that the individuals divide their lives into before, during, and after the injury, reliving the causal moment continuously. The family is essential to the individual's (re)adaptation. Nurses must improve their knowledge regarding spinal cord injury in order to support the individual, their family and the health care team.

Descriptors: Nursing Care; Rehabilitation; Spinal Cord Injuries.

\section{RESUMEN}

La lesión medular es una deficiencia física de gran impacto personal y social. Es grave e incapacitante. El estudio objetivó comprender los impactos de la lesión medular en la vida de la persona que la sufre. También fueron investigadas algunas características de las personas, realización de actividades cotidianas, la vida antes de la lesión, los recursos buscados al momento de la lesión. Estudio cualitativo, exploratorio y descriptivo. Participaron personas con lesión medular más antigua que dos años. La recolección de datos se basó en entrevista semiestructurada. Los resultados demostraron que la persona divide su vida entre antes, durante y después de la lesión, reviviendo el momento generador en diversas ocasiones. La familia es esencial en la (re)adaptación de la persona. Es necesario que el enfermero perfeccione sus conocimientos sobre lesión medular y sus cuidados, para brindar apoyo a la persona, a su familia y al equipo de salud.

Descriptores: Cuidados de Enfermería; Rehabilitación; Lesiones de Médula Espinal.

\footnotetext{
1 Enfermeira, Doutora em Filosofia da Saúde e Enfermagem, Professora Adjunto I, Universidade Federal de Santa Catarina (UFSC). Florianópolis, SC, Brasil. E-mail: soraia@ccs.ufsc.br.

${ }^{2}$ Enfermeiro, Hospital Santa Catarina. Criciúma, SC, Brasil. E-mail: rodolfonbitt@hotmail.com.

${ }^{3}$ Enfermeira, Doutora em Enfermagem, Professora efetiva, Universidade do Vale do Itajaí. Itajai, SC, Brasil. E-mail: mtl@soldasoft.com.br.

${ }^{4}$ Enfermeira, Doutora em Ciências Sociais, Professora Associado, UFSC. Florianópolis, SC, Brasil. E-mail: piresdp@yahoo.com.

${ }^{5}$ Enfermeira, Professora especialista, Universidade do Extremo Sul Catarinense. Florianópolis, SC, Brasil. E-mail: mbz@unesc.rct-sc.
} 


\section{INTRODUÇÃO}

Pesquisa global aponta que $15,6 \%$ de toda a população mundial adulta é composta por pessoas com algum tipo de deficiência, e que este percentual varia de $11,8 \%$ nos países mais ricos, a $18 \%$ nos mais pobres ${ }^{(1)}$. Ainda segundo estimativas, atualmente "existem 600 milhões de pessoas com deficiência, sendo que 400 milhões vivem em países pobres ou em desenvolvimento"(2).

No Brasil, investigações sobre deficiência física e o perfil epidemiológico destas pessoas são necessárias para nos possibilitar conhecer o que causou a deficiência, quem são, onde estão e como elas vivem. Os dados atuais sobre deficiência em nosso país remontam os do Censo do IBGE de 2000 e não permitem a diferenciação entre as diversas deficiências (intelectual, física ou múltipla) ${ }^{(3)}$. Análise da grade curricular de um curso de graduação em enfermagem evidenciou que este não possui disciplinas voltadas a esta temática ${ }^{(4)}$.

Disto apreendem-se duas questões: a primeira é o censo do IBGE demonstrar o desconhecimento sobre quem são e onde estão estes sujeitos; e, a segunda é que a temática da deficiência e da necessidade de cuidados às pessoas que fazem parte deste grupo, precisa ser investigada e considerada na formação dos profissionais de enfermagem.

A lesão medular é parte importante das deficiências físicas e também carecemos no Brasil de pesquisas que aprofundem o tema sob os diversos aspectos nele envolvidos. É caracterizada por alterações motoras e sensitivas negativas e distúrbios neurovegetativos abaixo da lesão(5) ${ }^{(5 ́}$ incapacitante para grande parte ou o restante da vida. Alguns estudos apontam a lesão medular relacionada principalmente à violência, resultante de acidentes, ferimentos por armas de fogo FAF, mergulho em águas rasa - MAR, e quedas ${ }^{(6-7)}$. É classificada em tetraplegia, quando afeta os quatro membros, ou paraplegia, quando compromete somente os membros inferiores. Ainda pode ser completa ou incompleta: a completa resulta em perda das funções motora e sensitiva abaixo da lesão e é denominada como American Spinal Injury Association ${ }^{(8)}$ (ASIA) (A). Quando incompleta, varia de ASIA (B) a (D), sendo $D$ aquela com menor sequela sensitivo-motora.

Atualmente, a lesão medular é considerada epidemia global(9). Estudo aponta que o Brasil tem a segunda maior incidência de trauma raquimedular do mundo: nele é estimado que anualmente haja 50 casos novos para cada um milhão de habitantes, o que indica a provável entrada, somente no ano de 2010 , de 96.000 novos casos de pessoas com lesão medular adquirida ${ }^{(9)}$.

O impacto causado na vida da pessoa que adquire uma lesão medular em qualquer fase é incomensurável, acarretando uma ruptura drástica entre a vida que tinha antes, e a nova, à qual terá que se (re)adaptar ${ }^{(10-11)}$. A pessoa se depara com uma condição completamente desconhecida, grave e incapacitante por um longo período de tempo, ou para o restante da vida, o que implica na auto-imagem, no reconhecimento da nova condição física, na relação com o mundo que a cerca, e com as pessoas que a cercam, numa relação de múltiplas determinações para o enfrentamento da nova vida. A pessoa com lesão medular pode apresentar sentimentos de "agressividade, insegurança, ansiedade, impulsividade, isolamento social, desespero, sentimento de inferioridade, ambivalência, raiva, medo e desesperança"(11).

Neste momento é que a família, a sociedade e os profissionais de saúde devem estar preparados para proporcionar-lhes todo apoio que auxilie no enfrentamento desta nova condição e no desejo de seguir a vida em frente, mesmo com as novas limitações e perspectivas. A família é condição essencial para a (re)adaptação da pessoa na reconstrução da vida. Embora somente ela possua a deficiência, todos familiares são afetados pela deficiência e ela se enxerga, se reflete e se apoia nos familiares ${ }^{(12-13)}$.

A ação do enfermeiro junto à pessoa com lesão medular também é de suma importância, visto que ela tem diversas demandas de cuidados terapêuticos que o enfermeiro é capaz de suprir para promover uma melhoria na qualidade da vida, além de auxiliar significativamente em todo o processo de reabilitação. Esta área do conhecimento é, para a Enfermagem, um campo muito vasto de saber a ser explorado, com muito a ser descoberto e investigado. É também uma área que depende da atuação interdisciplinar, o que coloca para a enfermagem imensa responsabilidade de contribuição prática e teórica.

Investigar sobre a vida das pessoas com lesão medular e o modo como elas a conduzem após a lesão é imprescindível, pois, a partir deste conhecimento tornarse-á possível aos profissionais de saúde e de enfermagem entender quais são as suas necessidades, 
contribuindo para que os cuidados sejam integral e humano, e para a (re)construção de uma vida digna e com qualidade.

Com base nestas reflexões buscamos por respostas sobre: o que acontece na vida da pessoa após a sua lesão medular e o impacto inerente às limitações decorrentes da lesão? A partir desta questão, surgiu o objetivo principal deste estudo que foi compreender quais os impactos da lesão medular na vida da pessoa por ela acometida.

\section{CAMINHAR METODOLÓGICO}

Pesquisa exploratória e descritiva, de abordagem qualitativa, que buscou compreender o impacto da lesão medular na vida das pessoas por ela acometidas e a investigação de aspectos da sua vida. A pesquisa qualitativa objetiva apreender o universo dos significados, dos motivos, das aspirações, das crenças, dos valores e das atitudes, na qual a profundidade dos dados é essencial e não é necessária a delimitação prévia da amostra, baseando-se a mesma na saturação dos $\operatorname{dados}^{(14)}$.

A pesquisa foi realizada em um município da região sul do estado de Santa Catarina. Para encontrar pessoas para participar da pesquisa, foram contatadas entidades associativas voltadas a esta população e sediadas neste município. A partir do contato inicial com as entidades e os possíveis participantes, foi feito contato via telefone com cada pessoa a fim de expor o propósito e os objetivos da pesquisa, confirmar a sua participação e, caso aceito, marcar a data e horário da entrevista em local por eles escolhido.

Participaram da pesquisa pessoas com lesão medular há pelo menos dois anos, residentes no referido município e que aceitaram participar do estudo. O tempo de, ao menos dois anos de lesão medular, foi critério de inclusão para que pudéssemos investigar os impactos da lesão na vida das pessoas. Foram contatadas oito pessoas com tais requisitos. Destas, três estavam impossibilitadas, uma não aceitou participar e quatro aceitaram. Os preceitos da norma 196/96 foram respeitados e os participantes assinaram o Termo de Consentimento livre e esclarecido- TCLE após esclarecimento. A coleta de dados foi iniciada após a aceitação do CEP/UNESC consubstanciada no parecer de número 139/2009.
A entrevista foi do tipo semi-estruturada, com base em roteiro, sendo dividida em três eixos principais: 1) a vida dos indivíduos antes da lesão; 2) o momento da lesão e suas implicações imediatas; 3) a vida após a lesão. A partir dos eixos pré-estabelecidos, os entrevistados foram estimulados a falar livremente, relatando suas experiências, dificuldades e impressões sobre os momentos de suas vidas. Cada entrevista durou, em média, duas horas e trinta minutos.

O registro dos dados foi feito por meio de gravação e posterior transcrição, e para sua análise utilizou-se de análise temática, que tem como perspectiva a compreensão dos significados no contexto da fala(14). Emergiram dos dados as seguintes categorias: 0 momento da lesão: e agora?; Vida após a lesão: este mundo não é o meu!; O (re) começo; Os suportes: família e redes de apoio e A vida, novas intercorrências. Os entrevistados foram nominados com a letra $P$ de participante, e o número sequencial de participação, os quais foram: P1, P2, P3 e P4.

\section{RESULTADOS E DISCUSSÃO}

\section{Características dos participantes}

$A$ idade dos participantes varia entre adulto jovem e adultos. P1 e P2 têm, respectivamente, 26 e 23 anos respectivamente (adulto jovem), e P3 e P4 mais de 40 anos. O tempo mínimo de lesão dos sujeitos de pesquisa foi de três anos e nove meses - P2, e o máximo de 36 anos - P3, o primeiro do sexo masculino e a última do sexo feminino.

O tempo decorrido entre a lesão e este estudo evidencia uma possível adaptação e maior conhecimento sobre os impactos da lesão medular. Com a mudança radical no corpo (sensitiva e motora) e na vida, há a necessidade de um tempo de (re)construção da finalidade, dos objetivos e da própria forma de viver, incluindo o enfrentamento de complicações decorrentes da lesão medular (úlceras por pressão, incontinência urinária/intestinal, sexualidade, acessibilidade).

A experiência individual mostra que o tempo é diferente para cada um e depende do apoio da família, da formação prévia, da idade, das causas da lesão, entre outros. Muito há para desvendar nesta realidade. Em relação à idade na época da lesão, todos a adquiriram quando adultos jovens, sendo P4 aquele que a adquiriu mais velho, com 36 anos. 
Os indivíduos participantes, antes da lesão, levavam uma vida normal, realizavam atividades cotidianas fazendo uso de autonomia e independência, possuíam relações de trabalho, estudo, interação social e afetiva.

Tinha uma vida normal, trabalhava, saia quase todos os finais de semana, quando tinha festas saia por tudo, era bem difícil ficar em casa, arranjava sempre alguma coisa pra fazer, jogava um vôlei, um futebol, alguma coisa assim. Tava namorando. (P2)

O nível da lesão nos participantes evidenciou que todos são paraplégicos. O nível da lesão é condição essencial e determina funcionalmente as capacidades de enfrentamento da vida. Apresentaram nível mais alto os participantes $\mathrm{P} 3$ e P4, respectivamente com 69 e 45 anos de idade, ambos com mais de nove anos de lesão.

No tocante à independência, a maioria utiliza o auxilio de terceiros na execução das AVDs. As atividades da vida diária dizem respeito àquelas relacionadas ao cuidado com o corpo - higiene, vestes, eliminações, alimentação e transferências. Interessante destacar que um indivíduo participante com o nível de lesão mais baixo - P2, e, portanto, sob o ponto de vista físico com maior possibilidade de independência, é justamente aquele que mais demanda a ajuda do cuidador, e, segundo ele, a ajuda é solicitada devido à existência de úlceras por pressão, uma complicação.

Quanto à escolaridade um tem estudo fundamental, três deles concluíram o ensino médio e destes um está cursando graduação. O nível de escolaridade pode implicar na capacidade de maior absorção das informações referentes ao enfrentamento da vida.

Os entrevistados jovens são solteiros, sem filhos, moram e contam com a ajuda dos pais; em contrapartida os outros dois, respectivamente P1 e P4 moram com seu cônjuge e filhos. A exceção de P2 que é evangélico, todos os outros são católicos.

P1 tem 26 anos, sofreu a lesão há quatro anos e 11 meses, após queda de uma laje. Tem curso superior completo, é solteira e não necessita de auxílio para as AVDs; P3 tem 69 anos sofreu a lesão há 36 anos como sequela de um tumor que comprimiu a medula, tem curso fundamental completo e é casada tendo quatro filhos; P4 tem 45 anos e possui a lesão há nove anos e seis meses, após acidente de motocicleta; é casado e fez ensino médio completo; e P2, com 23 anos, cuja lesão foi há três anos e nove meses, é solteiro e também fez curso médio. Com exceção de $\mathrm{P} 1$, os outros precisam de auxilio nas AVD - atividades da vida diária.

\section{O momento da lesão: e agora?}

O momento do evento que causou a lesão torna-se marcante, principalmente pelo caráter inesperado da situação, com consequências imprevisíveis e inesperadas. No momento da lesão, apesar da esperança de reversão da situação, há a consciência imediata da gravidade da situação, da perda dos movimentos e do mundo desconhecido que se descortina. A ruptura entre a vida anterior e a que se apresenta é percebida em toda sua plenitude e dimensão. Estudo sobre o momento do trauma e suas implicações remonta o ano de 2001, e coloca que há "re-experiência traumática"(15) constante, na qual a pessoa a revive como experiência contemporânea, e não como parte do passado.

Na hora do acidente fiquei calma comecei a tirar as minhas jóias, a minha amiga estava desesperada do meu lado, ela chorando e eu dizendo calma, calma eu to bem.... bem eu não tava né mas era pra elas ficarem bem; aí outra amiga dizia não te mexe não te mexe até os caras chegarem, porque já dava pra ver que tinha sido grave. Na hora eu pensei: Pá! me ralei, ferrou minha vida né. Já imaginava o que tinha acontecido, não sentia as pernas, tentei levantar a principio mais ai não deu então disse OPA! (P1)

No relato dos participantes, percebe-se que nos momentos que precedem o evento, há uma sucessão de pequenos acasos que culminam no evento gerador do trauma:

Então, na quarta feira que eu ia voltar, e eu ia começar a trabalhar no outro dia. Daí a gente inventou de subir na casa de dois pisos do meu padrinho na laje pra bater foto, era a ultima pose da máquina, e diziam: 'Ah vamos bater ali, vamos bater ali'. Daí, nessa laje tinha uma muretinha e a gente se encostou nós três, e o meu irmão mais novo batendo a foto. Daí nós nos encostamos, no que elas saíram pra frente depois que a gente bateu a foto, o muro cedeu e eu cai. Cai em cima de um meio fiozinho assim, daí foi onde eu quebrei minha coluna e tive quatro vértebras lesionadas e atingiu a medula e na mesma hora já paralisou os movimentos. (P1) 
Em todos depoimentos é mencionada esta cadeia de pequenos acontecimentos geradores. As pessoas acometidas revisitam incessantemente o momento do trauma, na busca do entendimento sobre o acontecido e das possibilidades de enfrentamento(11-12,15). A partir deste retorno ao momento $D$ torna-se possível repensar e reinterpretar os fatos de modo a reconstruir relações e acontecimentos.

Importante salientar que a manipulação da pessoa no local do acidente determina o futuro da lesão. Também a conduta dos profissionais de saúde e de socorro no momento do trauma é responsável, muitas vezes, por causar a lesão ou até mesmo fazer uma segunda lesão. O cuidado da pessoa no momento do acidente auxilia a evitar um segundo dano. Esta é uma questão crítica, pois, se há demora do socorro, o acidentado pode querer fazer esforços para mexer-se, os amigos querem ajudar, enfim, há aqui, também, situações casuais que podem mudar o rumo das sequelas de um acidente.

Fiquei meio zonzo, sem saber o que tinha acontecido, e os outros carros que passaram por ali, chegaram e desviraram o carro com a gente tudo dentro, né, pior ainda que daí deu outra batida. Na hora que desviraram o carro, eu voltei a mim e os caras começaram a sair de dentro do carro, e eu fui pra sair também, mas não consegui, daí já coloquei a mão na perna não sentia mais a perna e logo em seguida já começou a doer o local ali da lesão. (P2)

Estes problemas citados podem ser considerados em parte responsabilidade do enfermeiro, pois entre os profissionais da equipe de saúde ele é participante essencial no cuidado em saúde, seja urgência ou reabilitação, e deve evitar ou minimizar consequências que possam dificultar a adaptação do individuo na nova vida após o trauma. Estudo realizado em 2003(16), com 494 profissionais de enfermagem, entre os quais 75 enfermeiros e 319 técnicos de enfermagem, com o objetivo de identificar e analisar o conhecimento da equipe de enfermagem sobre o cuidado prestado ao lesado medular, desde a fase pré-hospitalar até sua alta, mostrou que pouco mais da metade $(54,4 \%)$ dos enfermeiros não se sente preparado para atender o lesado medular dentro do hospital. Este mesmo estudo, na análise da descrição de todos os passos para se assistir uma vitima no período pré-hospitalar, apenas seis enfermeiros e sete técnicos demonstraram ter o conhecimento adequado.

\section{Vida após a lesão: este mundo não é o meu!}

O enfrentamento da lesão e da nova forma de ver foi diferente para aqueles que já possuíam uma família em relação aos outros. Os dois entrevistados (P3 e P4) que possuíam família estruturada, casados e com filhos na época da lesão, aparentaram ter mais estabilidade afetiva.

Hoje tenho uma vida normal, saio pra dançar com meu marido, meus filhos e netos estão sempre ao meu redor, continuo minhas costuras. (P3)

Confunde-se com isso a idade na época da lesão, já que os mesmos tinham idade maior quando da lesão. Estudo sobre a qualidade de vida com pessoas com lesão medular demonstra que elas têm algumas dificuldades sexuais, o que torna mais difícil a busca de um parceiro e a estabilidade afetiva após a lesão(17).

Após a lesão, o indivíduo fatalmente depara com novas limitações a muitas atividades que antes realizava de forma independente. Depois da lesão, passou a necessitar de auxilio e de supervisão de outros. Equilibrar dependência e autonomia é uma linha muito tênue e se confunde com frequência nas relações sociais da pessoa com lesão medular(11-13-17).

A fragilidade percebida pela incapacidade no momento posterior à lesão foi marco comum entre os sujeitos entrevistados. A retomada de atividades cotidianas e a aquisição de novas habilidades para continuar tocando a sua vida, sem a presença constante de um acompanhante, é parte integrante da mudança radical da vida:

O fato de não poder fazer as coisas básicas, como tomar banho, escovar os dentes, isso me deixava muito chateada, às vezes eu queria algo na hora e tinha que esperar a vontade das pessoas, dai é complicado. (P1)

A capacidade de tocar a vida após a lesão varia muito em cada pessoa. Um ponto comum entre todos foi o isolamento social, ao menos no início da nova vida. Alguns, com o avanço da idade e de tempo de lesão, foram se adaptando à nova vida, reinserindo-se na vida social. Outros, por diversas razões, ainda optam por não 
sair de casa, acirrando o isolamento que a sociedade excludente que vivemos impõe. As inúmeras sequelas de uma lesão medular transformam de forma significativa a vida dos indivíduos, tanto nos aspecto físico, como emocional, ocupacional, social, relacional, valorativo e de auto-percepção. Isso pode gerar medo, desesperança e sentimento de inferioridade, o que leva ao isolamento social pela própria dificuldade de expressar emoções e dar continuidade em um processo de busca da independência e autonomia. Associa-se muito ainda a idéia da deambulação, como fator determinante para a convivência dos indivíduos na sociedade, como se o aspecto físico fosse determinante para a volta de sua participação no meio social(11).

Não tive namorada... no começo até tive mais não me sentia bem, estranho. Daí foi passando o tempo, eu não sou muito de sair mesmo. Tipo assim, eu não gosto de sair muito na rua, por causa disso o cara sai de casa e fica todo mundo olhando, por isso que eu já não gosto de sair muito. (P2)

A dificuldade de marcha causa em muitas pessoas uma incapacidade em gerar gratificações e prazer para si e para os outros a sua volta. É necessário, nesse momento, que lembremos o individuo de seu passado e de seus feitos, salientando ainda que a lesão medular é uma parte de sua vida, sim, mas que ele possui uma série de outras características e atribuições não menos importantes e que ele é capaz de executar.

O rompimento do isolamento social é fundamental para compor essa nova vida e é conseguido após a reflexão dos adjetivos e características pessoais com o auxilio de uma equipe de saúde preparada para tal. Apenas com a interação social o individuo poderá descobrir novas maneiras de locomoção, caminhando na sociedade, reconhecendo que as dificuldades na deambulação, movimentação de membros e perda de controle dos esfíncteres não são empecilho para uma vida social ativa e autônoma. Importante considerar que a saída dos lesados medulares de casa para viver a vida em sociedade gera ganhos para os próprios indivíduos, bem como auxilia na transformação da sociedade, na medida em que aumentará a oportunidade de observarem que as pessoas com lesão medular existem e possuem necessidades, sim, e que têm valores e potenciais inestimáveis. Fazendo com que o respeito à diversidade humana seja preservado.

\section{O (re) começo}

Estudo(11) apontou que na fase de pré-reabilitação existe uma maior diferenciação entre as estratégias dos indivíduos e familiares, enquanto que na fase pósreabilitação há uma busca maior pela independência e volta à vida. Os programas de reabilitação influenciam o modo de enfrentamento dos lesados medulares, podendo mobilizá-los a buscar estratégias que viabilizem uma melhor adaptação a essa nova vida. A reabilitação prevê a clareza das informações e o repasse das mesmas, integrando sempre a questão sócio-familiar, melhorando a qualidade de vida de todos os envolvidos(18-19). O processo de reabilitação, salvo exceções, deve ser iniciado logo após a lesão. Infelizmente, na realidade brasileira, a reabilitação demora para ser iniciada, por pura falta de acesso aos serviços especializados:

Então, essas coisas de fazer toque, controlar a bexiga, aprendi lá no Sarah, em setembro de 2007. Consegui ir pra lá por intermédio da Secretária da saúde, eles fizeram o TFD (tratamento fora do domicílio) e fiquei esperando quase um ano e aí me chamaram fiquei lá um mês, foi aí que eu aprendi tudo. Até então, minha mãe fazia tudo, toque, banho, tudo... no hospital XXXX, eles já ensinaram o cateterismo e a lidar com o intestino também.. mas ensinaram a mãe, não ensinaram a mim e eu consigo fazer tudo, achei que nunca ia fazer reabilitaçao. (P1)

Os diversos papéis desenvolvidos pelo enfermeiro em sua formação, tanto como educador, gerente, e prestador de assistência, coordenando e determinando a administração da assistência, tanto para o individuo quanto para sua família pode ser de grande poder terapêutico, não no sentido de curar a lesão, mas em termos de chegar ao melhor bem estar possível. O enfermeiro é peça fundamental para o bom andamento do trabalho na reabilitação, funcionando como elo de integração na equipe de assistência(18).

Quanto à assistência de Enfermagem e o Processo de Reabilitação, estudos mostram a sua importância "auxiliando o paciente a viver com o mínimo de dependência, dentro de suas condições. Através de ações educativas continuadas visando membros da própria equipe, pacientes e cuidadores, os enfermeiros 
tornam-se os instrumentos da modificação de atitudes e conceitos e produzem melhoria concreta do atendimento oferecido a esses pacientes" (19).

\section{Os suportes: família e redes de apoio}

Nesses momentos em que os lesados experimentam as limitações em sua vida, a presença da família é fundamental para dar todo o suporte necessário:

E a minha mãe aqui, toda a minha família aqui. Meu padrinho veio até aqui buscar ela. Chegaram lá em Floripa já era nove horas, assim que eu sai da cirurgia a mãe chegou lá. Ela ficou lá comigo os doze dias que eu fiquei no hospital. Sentadinha numa cadeirinha do meu lado. Passei um dobrado e minha mãe sempre ali do meu lado na cadeirinha. A mãe é mãe né, estava sempre do meu lado, mais tinha vezes em que ela não estava, daí tinha que esperar, né. (P1)

A família terá, depois, a função de cuidar do individuo em casa, desenvolvendo suas atividades da vida diária, até que o mesmo recupere o controle de si mesmo, ainda que parcialmente. Nesse emaranhado, ocorrem profundas mudanças que a afetam diretamente, já que todos terão de se adaptar a essa realidade. Esse momento é rodeado de sentimentos, como o medo, a incerteza e o sofrimento. Cada família reagirá de forma distinta, porém o que se espera é que essas mudanças ocorram, para que a família possa participar ativamente de todo o processo de reabilitação.

Em um dado momento ocorre o momento da escolha do cuidador dentro da própria família, fazendo com que o mesmo aprenda os primeiros cuidados, até o alcance do ajustamento familiar. Sua participação no momento da reabilitação é indispensável, não apenas para cuidar do sujeito, mas para proporcionar a ele subsídios para o enfrentamento, compreensão e compartilhamento da situação de deficiência, auxiliandoo a enfrentar os próprios problemas e conflitos pessoais ${ }^{(13)}$.

A família precisa aprender a cuidar, conforme estudo realizado ${ }^{(20)}$ diz que "é relevante enfatizar a necessidade do treinamento da mesma através do planejamento de atividades (envolvendo a equipe de saúde) durante o processo de internação de orientar o paciente, e mostrar, de forma mais organizada, os cuidados necessários com o paciente, esclarecer suas dúvidas e certificar-se da incorporação das orientações dadas a ela".

As Redes Sociais são as grandes responsáveis por auxiliar as pessoas com lesão medular a continuar tocando suas vidas com a nova realidade, de modo que quanto mais integrados a essas frentes mais elas têm possibilidades de crescimento individual e de auxilio a outras pessoas em condição semelhante:

Em 2007, depois que eu voltei do Sarah, conheci a associação (JUDECRI) e foi ali que eu sai de casa pois ate então eu não saia. Daí conheci o C. (integrante da JUDECRI) que trabalha com a gente ali na associação e ele me estimulou a começar a fazer academia com eles ali. $E$ comecei a praticar arremesso de dardo, de peso e ai comecei a fazer e estou até hoje. Ai me incentivou a começar a fazer faculdade, que até então tinha interesse mas não tinha coragem de começar a fazer, até pelo medo de enfrentar a sociedade, tudo isso também eu tive que ir formulando, trabalhando com isso, porque eu achei que nunca ia conseguir andar de ônibus, andar na rua. (P1)

\section{A vida, novas intercorrências}

São comuns as diversas intercorrências na pessoa com lesão medular: problemas vesico urinários, úlceras de pressão, incontinência intestinal, espasticidade são as mais comuns. A intercorrência mais citada pelos entrevistados foram as úlceras de pressão, tendo como motivos principais pelo seu desenvolvimento a falta de cuidado da equipe de saúde, falta de experiência da família, uso de superfícies inadequadas para repouso das proeminências ósseas.

Depois que eu comecei a sair de casa, fiquei com escara, porque antes de ir pro Sarah nunca tinha usado nenhuma almofada especial. Daí, depois, comecei a usar, tive que parar de treinar por casa disso. Não chegou a abrir muito, ficou só na pele. Mais foi por descuido meu. (P1)

Um estudo realizado(20) demonstra que $73,3 \%$ dos pacientes estudados apresentavam cuidados adequados com a pele, em contrapartida, no momento da pesquisa, $26,7 \%$ não se apresentavam com a pele íntegra, sendo causadas por agentes físicos, químicos ou biológicos. $O$ lesado medular é muito vulnerável ao desenvolvimento de úlceras por pressão, por diversas razões, que incluem 
a degradação do colágeno e as sequelas circulatórias decorrentes da lesão da medula espinhal que acabam comprometendo o fluxo sanguíneo periférico. A transpiração, incontinência fecal e urinária aumentam consideravelmente a umidade da pele, fazendo com que a mesma se torne mais vulnerável ao trauma. O estudo ainda mostrou que, dos pacientes que apresentaram alteração do tegumento, cerca de $20 \%$ desenvolveram as úlceras por pressão. O autor ainda esclarece que, com a perda da mobilidade e da sensibilidade abaixo do nível da lesão, como fatores principais para a ocorrência das mesmas, pode ainda causar sérias complicações como a osteomielite, septicemia, podendo levar o paciente à óbito.

O controle vesical e intestinal é comum a todos os lesados e cada um, conforme as orientações que recebeu, adapta-se de uma forma diferente. O enfermeiro, nessa área, é o profissional responsável pela reeducação dos mesmos, que deve ocorrer precocemente, logo no inicio da lesão e é responsável pelo sucesso ou fracasso da reeducação.

Hoje eu faço cateterismo, eu sinto arrepio e vou no banheiro, às vezes é normal, outras vezes tenho que fazer o processo, né, às vezes massagem, às vezes toque, uso Minilax, quase todo dia vou ao banheiro, tento não usar muito o supositório. (P4)

\section{CONCLUSÕES}

Neste momento de finalização, que sabemos tratase apenas do começo, é necessário retomarmos os objetivos deste estudo, cujo foco foi conhecer os impactos da lesão medular na vida da pessoa e alguns aspectos de sua vida, principalmente a forma que as mesmas conduziram suas vidas após a lesão.

A lesão medular acarreta mudanças profundas no funcionamento do organismo. As pessoas atravessam um período de profundo aprendizado, no qual têm que lidar intensamente com suas limitações. Essas mudanças demandam adaptações físicas, emocionais e sociais, que determinam o surgimento de novos padrões de vida. Considerando que a grande maioria das pessoas com lesão medular está na juventude ou idade adulta jovem, é vital que a sociedade esteja preparada para ampará-las, permitindo que elas retornem à vida de uma maneira saudável e que, de acordo com sua vontade, sejam estimulados a se sentirem produtivas.

A vida dos participantes anterior à lesão era como a da maioria das pessoas: desempenhavam atividades de estudo, trabalho e lazer, vivendo com amigos e familiares e usufruindo das possibilidades que a vida coloca a alguém com o domínio completo de motricidade e sensibilidade.

Em contrapartida, o momento da lesão evidenciou semelhanças quanto às reações de cada pessoa, especialmente na descrição muito pormenorizada dos mínimos detalhes do momento e na certeza momentânea de uma mudança radical e do desconhecimento do futuro. Ficou evidente que a pessoa, após a lesão revê e reflete infinitas vezes sobre o momento do evento, isto como parte essencial da tentativa de enfrentar a nova condição.

Quanto aos impactos da lesão medular sobre a vida da pessoa, estes estão relacionados, por um lado a sua própria vida e antecedem à lesão: dependem da idade, da estrutura familiar, e dos laços estabelecidos. Por outro lado são as complicações e comorbidades a ela associadas. No entanto, a forma como cada um enfrenta estas complicações também é dependente da vida anterior, numa determinação dialética entre vida anterior (família, laços, história, conhecimento, nível sócio econômico), com algumas limitações e possibilidades e vida atual com outras limitações e possibilidades. Após a lesão medular a pessoa se depara com uma vida completamente diferente da anterior, desconhecida, com outros questionamentos e prioridades e, para vivê-la, se utiliza de todo arcabouço afetivo de sua história.

O enfermeiro deve conhecer mais sobre a lesão medular, suas intercorrências, e as formas de intervenções possíveis, apostando sempre na capacidade que o outro possui e na vida que há pela frente. As possibilidades de intervenção de enfermagem são tantas, seja na atuação apenas da equipe de enfermagem, quanto na equipe multiprofissional, sempre como um elo forte de ligação entre o individuo que precisa de ajuda e os outros profissionais. Os profissionais enfermeiros devem estar mais atentos no cuidado dos indivíduos com lesão medular, sempre apoiando na continuação de suas vidas.

A importância e o significado desse estudo, enquanto investigação de e para a enfermagem, resulta 
de seu compromisso precípuo com o bem estar das pessoas as quais apoia. É possível e necessário que o enfermeiro atue como responsável pelas ações de saúde que visam prevenção, promoção e recuperação e

\section{REFERÊNCIAS}

1. World Health Organization. The World Bank. World report on disability. Geneve: WHO; 2011 [cited 2011 out 31]. Avaiable from: http://whalibdoc.who.int/publications/2011/9789240685215 eng.p $\underline{\mathrm{df}}$

2. Secretaria Especial dos Direitos Humanos; Coordenadoria Nacional para a Integração da Pessoa Portadora de Deficiência CORDE (BR). A convenção dos direitos da pessoa com deficiência comentada. Brasília: Secretaria Especial dos Direitos Humanos; 2008.

3. Instituto Brasileiro de Geografia e Estatística [Internet]. Brasília: Ministério do Planejamento, Orçamento e Gestão (BR) [cited 2011 out 31]. Censo de 2000. Questionário da amostra. Avaiable from: http://www.ibge.gov.br/censo/questionarios.shtm

4. Universidade Federal de Santa Catarina. Guia dos estudantes do curso de graduação em enfermagem. Florianópolis, 2008.112p.

5. Melo ACR. Descrição da aptidão inicial para natação em lesionados medulares. Rev Bras Med Esporte [Internet]. 2009 [cited 2011 out 15]; 15(6):441-5. Avaiable

from: http://www.scielo.br/scielo.php?script=sci_arttext\&pid=S1517 $-86922009000700008 \&$ lng=pt\&nrm=iso\&tlng=pt

6. Rede Sarah de Hospitais de Reabilitação [Internet]. Brasília: Rede Sarah de Hospitais de Reabilitação (BR) [cited 2011 mar 03].

Avaiable from: http://www.sarah.br

7. Alves ALA, Salim FM, Martine EZ, Passos ADC, de Carlo MMRP, Scarpelini S. Qualidade de vida de vítimas de trauma seis meses após a alta hospitalar. Rev Saúde Pública 2009; 43(1):154-60.

8. American Spinal Injury Association International [Internet]. Michigan: Website Design by MCG Web Development (EUA) [cited 2011 out 31]. International standards for neurological classification of spinal cord injury. Avaiable from: http://www.sci-info-pages.com/ 9. Fawcett JW, Curt A, Steeves JD, Coleman WP, Tuszynski MH, Lammertse $D$ et al. Guidelines for the conduct of clinical trials for spinal cord injury as developed by the ICCP panel: spontaneous recovery after spinal cord injury and statistical power needed for therapeutic clinical trials. [Internet]. Cambridge: International Spinal Cord Societ [cited 2011 mai 18]. Avaiable from:

http://www.campaignforcure.org/iccp/index.php?option=com_cont ent\&task=view\&id=13\&ltemid=28.

10. Medola FO, Busto RM, Marçal AF, Junior AA, Dourado AC. O esporte na qualidade de vida de indivíduos com lesão da medula espinhal: série de casos. Rev Bras Med Esporte [Internet]. 2011 [cited 2011 nov 22];17(4):254-6. Available from: http://www.scielo.br/scielo.php?script=sci arttext\&pid=S1517$86922011000400008 \& \operatorname{lng}=e n \& n r m=i s o$.

11. Fechio MB, Pacheco KMB, Kaihami HN, Alves VLR. A repercussão da lesão medular na identidade do sujeito. Acta Fisiatr. 2009;16(1):38-42

12. Murta S, Guimarães SS. Enfrentamento à lesão medular traumática. Estud. psicol. 2007;12(1):57-63.

13. Pereira MLMSM, Araujo TCCF de. Enfrentamento e reabilitação de portadores de lesão medular e seus cuidadores. Psico. 2006;37(1):37-45.

14. Minayo MCS. O desafio da pesquisa social. In: Minayo MCS, Deslandes SF, Gomes R. Pesquisa social: teoria, método e criatividade. 28. ed. Rio de Janeiro: Vozes; 2009. p. 9-79. 15. Filho JWSC, Sougey EB. Transtorno de estresse pós-traumático: formulação diagnóstica e questões sobre comorbidade. Rev. Bras. Psiquiatr. 2001;23(4):221-8.

16. Cavalcante ES, Farias GM, Santos KN dos. Conhecimento da equipe de enfermagem no processo de cuidar às vítimas de traumatismo raquimedular. Inter Science Place. 2009;2(6):1-11. reabilitação dos indivíduos portadores de lesão medular, e, para isto, tem o dever ético de buscar informação para apreender os caminhos para ser efetivamente apoiador para a construção da reabilitação.

17. Bampi LNS, Guilhem D, Lima DD. Qualidade de vida em pessoas com lesão medular traumática: um estudo com o WHOQOL-bref. Rev. bras. epidemiol. 2008;11(1):67-77 .

18. Andrade LT, Araújo EG, Andrade KRP, Soares DM, Cianca TCM. Papel da enfermagem na reabilitação física. Rev Bras Enferm. 2010;63(6):1056-60.

19. Melo VR de, Martins C. O papel do enfermeiro na assistência e reabilitação do paciente portador de lesão medular. Neurob. 2009;72(1):53-6.

20. Cardozo GRI, Villa TCS e Caliri MHL. O processo da assistência ao paciente com lesão medular: gerenciamento de caso como estratégia de organização da alta hospitalar. Medicina (Ribeirão Preto). 2001;34(3/4):325-33.

Artigo recebido em 22.11.2010.

Aprovado para publicação em 13.03.2012.

Artigo publicado em 30.03.2012. 